\title{
MYC is a critical target of FBXW7
}

\author{
Mai Sato ${ }^{1,2}$, Ruth Rodriguez-Barrueco ${ }^{2,5}$, Jiyang $\mathbf{Y u}^{3}$, Catherine Do ${ }^{2}$, Jose M. Silva ${ }^{1,2,5}$ \\ and Jean Gautier ${ }^{2,4}$ \\ ${ }^{1}$ Department of Pathology and Cell Biology, Columbia University, New York, USA \\ 2 Institute for Cancer Genetics, Columbia University, New York, USA \\ ${ }^{3}$ Department of Biomedical Informatics, Columbia University, New York, USA \\ ${ }^{4}$ Department of Genetics and Development, Columbia University, New York, USA \\ ${ }^{5}$ Department of Pathology, Mount Sinai School of Medicine, New York, USA \\ Correspondence to: Jean Gautier, email: jg130@columbia.edu \\ Keywords: MYC, FBXW7, synthetic lethality, CDC45, MCF10A
}

Received: November 13,2014 Accepted: December 18,2014 Published: December 26, 2014

This is an open-access article distributed under the terms of the Creative Commons Attribution License, which permits unrestricted use, distribution, and reproduction in any medium, provided the original author and source are credited.

\section{ABSTRACT}

MYC deregulation is a driver of many human cancers. Altering the balance of MYC protein levels at the level of transcription, protein stability, or turnover is sufficient to transform cells to a tumorigenic phenotype. While direct targeting of MYC is difficult, specific genetic vulnerabilities of MYC-deregulated cells could be exploited to selectively inhibit their growth. Using a genome-wide shRNA screen, we identified 78 candidate genes, which are required for survival of human mammary epithelial cells with elevated MYC levels. Among the candidates, we validated and characterized FBXW7, a component of the SCF-like ubiquitin ligase complex that targets MYC for proteasomal degradation. Down-regulation of FBXW7 leads to synergistic accumulation of cellular and active chromatin-bound MYC, while protein levels of other FBXW7 targets appear unaffected. Over a four-week time course, continuous FBXW7 down-regulation and MYC activation together cause an accumulation of cells in S-phase and G2/M-phase of the cell cycle. Under these conditions, we also observe elevated chromatin-bound levels of CDC45, suggesting increased DNA replication stress. Consistent with these results, FBXW7 down-regulation alone decreases the survival of T47D breast cancer cells. These results establish that FBXW7 downregulation is synthetic lethal with MYC, and that MYC is a critical target of FBXW7 in breast epithelial cells.

\section{INTRODUCTION}

Genetic and epigenetic events altering the expression, the stability, or the activity of oncogenes and tumor suppressor genes participate in the initiation and maintenance of human cancers [1]. Among the genes which expression is modified in cancer, only a relatively small subset is recurrently altered and contributes to the tumorigenic phenotype [2]. Identification of such "cancer driver genes" has facilitated the development of targeted treatment options in the recent years, yet there are still pharmacological limitations that hinder direct targeting of some major cancer drivers including MYC [3].

The MYC proto-oncogene is deregulated in over half of human cancers including hematopoietic cancers, sarcomas, and carcinomas [4]. MYC is essential for normal cell growth. In particular, MYC is required for cell proliferation and is involved in differentiation, metabolism, and apoptosis, most notably through its function as a bHLH-LZ transcriptional activator and repressor [5]. In addition, MYC has direct, transcriptionindependent functions in DNA replication [6] and protein synthesis [7], further supporting its major role in cellular homeostasis. Therefore, cellular MYC protein levels are tightly controlled through regulated expression [8], protein stability [9], and degradation [10]. Indeed, alterations in MYC abundance are a critical component of MYCdependent tumorigenesis [11]. 
At least 4 different ubiquitin ligase complexes can target MYC for proteasomal degradation [10], including the SCF-like ligase complex containing FBXW7 [12, 13]. FBXW7 (or Fbw7, Sel-10, hCdc4, hAgo) is an F-box protein that confers substrate specificity for this complex [14]. MYC is a documented target of FBXW7. However, FBXW7 also targets several additional oncoproteins and master regulator molecules including CyclinE, NOTCH1, mTOR, SREBP, and c-JUN, among others [14] and the respective contributions of FBXW7-dependent regulation of these proteins towards abnormal cell growth is not known. Moreover, although the role of FBXW7 as a tumor suppressor is well documented in hematopoietic tumors in which mutations in FBXW7 are unequivocally linked to tumorigenesis [15], this is not as clear for other cancer types $[16,17]$. For example, it has been reported that the inactivation of FBXW7 can be associated with favorable prognosis in a subset of breast cancers [18], suggesting that the physiological role of FBXW7 and consequences of its loss may be dependent on cell types and contexts.

Exploring synthetic lethality has provided many critical insights into the biology of oncogenes [19]. In addition, identifying genes that are essential to cope with activated oncogenes might provide alternatives to direct targeting for cancer therapy [20]. In the case of MYC, several genes which loss is synthetic lethal with aberrant MYC expression have been identified. These include DR5 in the death receptor pathway [21], the WRN helicase [22, 23], the AuroraA/B [24] and CDK [25, 26] cell-cycle kinases, and Chk1/2 [27, 28]. More recently, genome-wide approaches have helped to identify the SAE1/2-dependent SUMOylation pathway [29] and CSNK1E kinase [30] as potential synthetic lethal candidates as well. Intriguingly, studies in different model systems appear to yield unique results, possibly due to MYC's cell-context specific roles and the differing modes of deregulation.

In the present study, we conducted a genomewide screen to identify genes that are required to survive MYC overexpression in MCF10A breast epithelial cells conditionally expressing a MYCER allele. We document these synthetic lethal interactions and identify 78 potential synthetic lethal targets. Among these, we have validated the F-box protein FBXW7 as a synthetic lethal candidate in MCF10A-MYCER cells overexpressing MYC. We show that shRNA-mediated knockdown of FBXW7 confers increased lethality to non-transformed MCF10A cells with activated MYCER and to T47D breast cancer cells. In MCF10A, active chromatin-bound MYCER is stabilized in cells with down-regulated FBXW7, while protein stability of other FBXW7 targets is not affected. We also find that knockdown of FBXW7 upon MYCER activation results in accumulation of cells in S/G2 phase with increased chromatin-bound CDC45. These results suggest that increased cellular MYCER levels as a result of FBXW7 loss yields sufficient cellular stress to confer selective lethality to those cells with deregulated MYC.

\section{RESULTS}

\section{MCF10A-MYCER cells: a model for MYC deregulation}

First, we sought to generate a cellular model for MYC conditional expression that recapitulates MYC deregulation in human cancer cells. To this goal, we stably integrated an inducible MYCER transgene [31] into MCF10A, a non-transformed breast epithelial cell line, via retroviral transduction. MYCER consists of a fulllength MYC cDNA fused to the hormone-binding domain of the murine estrogen receptor. This ER fragment does not respond to estrogen [31]. Upon treatment with the synthetic ligand 4-hydroxytamoxifen (4OHT), MYCER protein is rapidly transported to the nucleus, rendering it active.

Following retroviral transduction, we selected a clone expressing MYCER (Figure 1A) that fulfilled two criteria: 1) normal levels of endogenous MYC expression were retained, and 2) MYCER was expressed at levels 2-3 fold higher than endogenous MYC, a level of MYC expression that is appropriate for modeling MYC deregulation in human cancers without MYC amplification [32] (Figure 1A). Following 4OHT treatment, this clone showed a 1.54 fold increase in active, chromatin-bound MYCER, demonstrating the anticipated 4OHT-dependent nuclear import and activation of MYCER (Figure 1B). Next, we tested the ability of the MYCER transgene to activate transcription. MCF10A-MYCER cells were transfected with a luciferase reporter construct harboring tandem E-box sequences, the canonical MYC DNA binding site (Supplementary Figure 1). Upon 4OHT treatment, we observed a 2.3 fold increase in reporter activity $(\mathrm{p}<0.0001)$, consistent with the increase in chromatin-bound MYCER (Supplementary Figure 1). Finally, we tested the ability of the transgene to accelerate entry into S-phase, another hallmark of MYC deregulation. Cells were synchronized at the G1/S transition by double thymidine block and labeled with BrdU following induction of MYCER. S-phase entry was then monitored by the appearance of BrdU foci assessed by indirect immunofluorescence. As anticipated, MYCER induction triggered marked acceleration of S-phase entry (Figure 1C and Supplementary Figure 2). These results establish the validity of MCF10A-MYCER to model a near physiological degree of MYC deregulation.

\section{Screen for synthetic lethal candidates with MYCER activation}

Next, we performed a genome-wide screen to identify genes which loss is synthetic lethal with aberrant MYC expression utilizing the GIPZ Lentiviral Human 
shRNA-mir Library (Thermo Scientific Open Biosystems, Waltham, MA, USA). The pooled shRNA plasmid library includes 58,493 shRNA constructs and targets 18,661 known human genes (2-3 shRNAs per gene covering $75 \%$ of entire genome) as described in Rodriguez-Barrueco et al [33]. We designed the screen based on negative selection, i.e. we monitored loss of shRNAs to identify the corresponding genes that render cells sensitive to MYCER activation by $4 \mathrm{OHT}$ when lost (Figure 2A).

The screen was performed in 5 independent replicates, which were utilized to generate $\mathrm{p}$-values for screening of statistically significant high-confidence candidates. Cells were initially transduced with the pooled shRNA library at $30 \%$ infection efficiency to achieve, on average, single-copy shRNA integration per cell. 200 million cells were infected in order to obtain at least 1000 cells with each shRNA from the library. Infected MCF10A-MYCER cells were first allowed to grow in the absence of MYCER induction for two generations to eliminate most shRNAs targeting essential genes. Then, the remaining cells were propagated in either the presence or absence of $4 \mathrm{OHT}$ for four weeks, maintaining a constant total cell number of at least 70 million per sample to preserve the representation of at least 1000 cells per shRNA construct. The surviving populations were harvested after four weeks, and genomic DNA was isolated (Figure 2A). The stably integrated shRNA constructs were then amplified by large scale PCR, labeled with fluorescent nucleotides, and hybridized to custom microarrays harboring complementary oligonucleotide probes to the unique 60 -nucleotide barcodes present on each individual shRNA.

The microarray analysis was performed as described in $\mathrm{Yu}$ et al [34] (Figure 2B). We identified 78 candidate genes for which the corresponding shRNAs had a Log2FC (fold change) value of -1 or less, thus, depleted 2-fold or more in the MYC ON population compared to MYC OFF with a $\mathrm{p}$-value of $\mathrm{p}<0.05$ across five replicates (Supplementary Table 1). Functional annotation clustering using the KEGG pathways in the DAVID Bioinformatics Database revealed that the most represented biological pathways within the synthetic lethal candidates included ubiquitin mediated proteolysis, PPAR signaling pathway, fatty acid biosynthesis, fructose and mannose metabolism, and homologous recombination (Figure 2C). Within the proteolysis pathway and among the top hits we identified UBE2I, the E2 conjugating enzyme cooperating with the SAE1/2 E3 ligase in the SUMOylation pathway. This is in agreement with previous reports in which SAE1/2 and UBE2I were identified in similar MYC-synthetic lethal (MYC-SL) screens [29, 30]. Using a set of independent shRNAs, we validated that loss of UBE2I is indeed synthetic lethal with MYCER activation in MCF10AMYCER cells $(p<0.0001)$, providing a proof of principle for our screen (Figures 2D and 2E).

Notably, three major MYC-SL screens have been published to date $[29,30,35]$. When comparing our dataset to these screens, we observed that FBXW7 was one of four MYC-SL hits that overlapped between our screen and Kessler's screen [29]. Additionally, the GSK3- $\beta$ kinase, which is required for MYC degradation by FBXW7, was found as one of the eleven top MYC-SL kinases from Liu's screen $[12,35]$. Moreover, the MYC ubiquitination and SUMOylation network was determined as one of three major functional MYC-SL hubs, in a comprehensive meta-analysis of the three published MYC-SL datasets [36]. These results suggest that FBXW7-dependent MYC degradation may be a significant MYC-SL pathway.
A

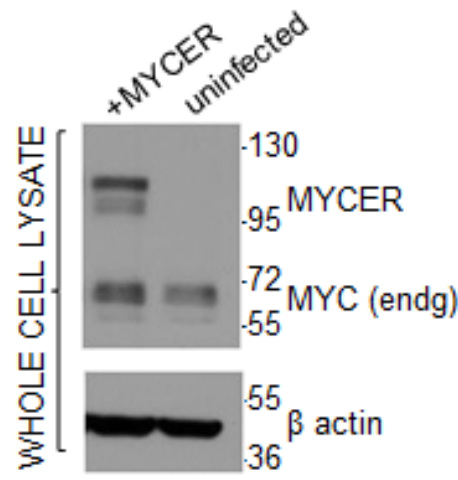

B

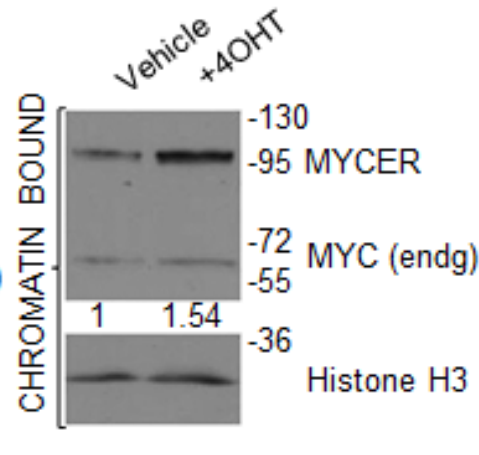

C

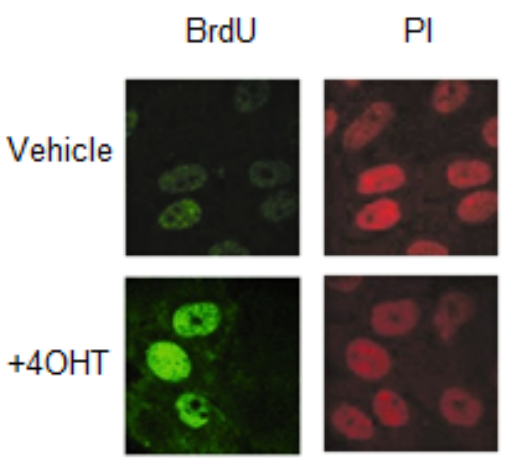

Figure 1: MCF10A-MYCER cells: a model for MYC deregulation. (A) MCF10A-MYCER cells express MYCER protein. Whole cell lysates from uninfected or MYCER-infected MCF10A cells were analyzed by SDS-PAGE. The positions of endogenous MYC and MYCER are indicated. (B) MYCER protein is activated in response to 4OHT treatment. Nuclear translocation of MYCER was analyzed by cell fractionation followed by SDS-PAGE of the chromatin-bound fraction from MCF10A-MYCER cells treated with vehicle or 200nM 4OHT for $48 \mathrm{hr}$. MYCER increase was normalized to histone H3 levels for quantification. (C) MYCER activation induces accelerated entry into S phase. MCF10A-MYCER cells were arrested at G1/S with double thymidine. Cells were treated with vehicle (ethanol) or 4OHT, then pulse labeled with BrdU $1 \mathrm{hr}$ after release into $\mathrm{S}$ phase. BrdU incorporation was assessed using indirect immunofluorescence. PI=propidium iodide was used to stain genomic DNA. 
Therefore, we selected FBXW7 for further analysis, which ranked $58^{\text {th }}$ in our high-confidence MYC-SL list with $\log 2 \mathrm{FC}=-1.1469(\mathrm{p}<0.02$, Supplementary Table 1).

\section{Loss of FBXW7 together with MYCER activation is lethal}

We elected to further validate FBXW7, the substrate recognition subunit of the SCF-like E3 ubiquitin ligase complex that regulates degradation of MYC and other oncoproteins [14]. First, we wanted to confirm that loss of FBXW7 is lethal when combined with MYCER activation. We generated cell lines stably expressing either constitutively expressed or doxycycline-inducible shRNA clones targeting different regions of FBXW7 to experimentally manipulate its abundance. Following lentiviral infection of stable shRNA constructs and antibiotic selection, FBXW7 knockdown levels were assessed by quantitative RT-PCR. Both constitutive and doxycycline-inducible shRNA clones yielded an average of $45 \%$ knockdown of FBXW7 mRNA levels (Figure 3A). We were unable to achieve further knockdown of FBXW7 in MCF10A-MYCER cells, suggesting a threshold level of FBXW7 is required for MCF10A-MYCER viability, even when the MYC transgene is off.

We utilized a fluorescence-based cell competition assay to compare the viability of FBXW7 knockdown cells in the absence or presence of $4 \mathrm{OHT}$ over a period of approximately four weeks, to recapitulate the experimental conditions of the screen and physiological modest deregulation of MYC. Since all shRNA constructs co-express GFP or RFP, cells expressing shRNA are readily detectable by fluorescence. A mixed population of $50 \%$ MCF10A-MYCER cells without shRNA and
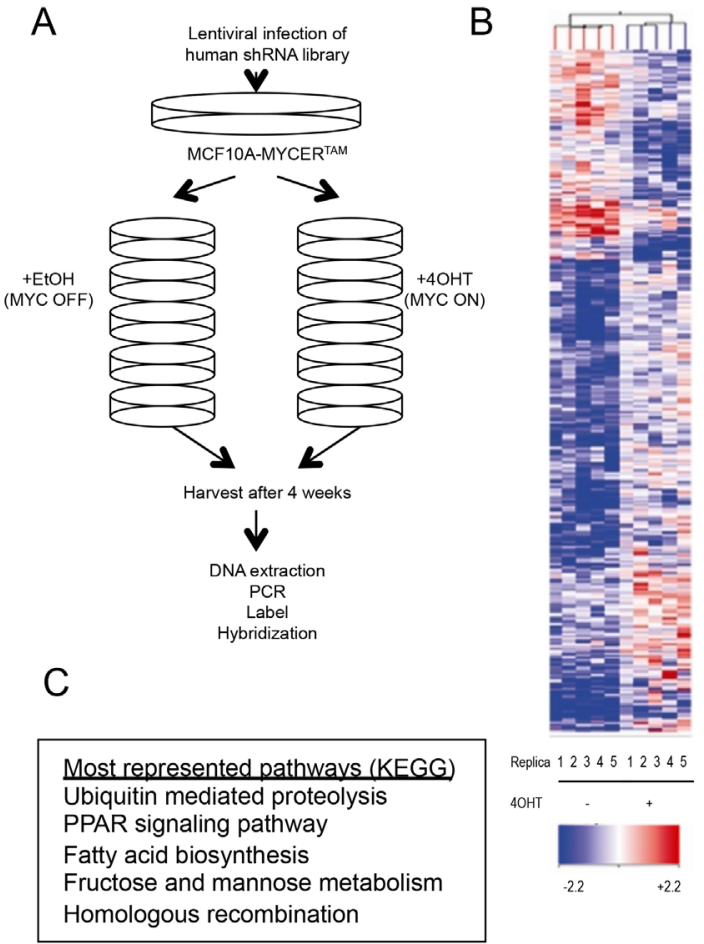

$\mathrm{D}$

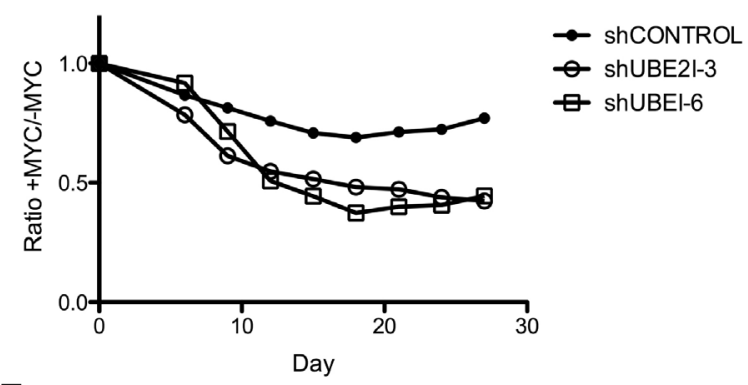

E

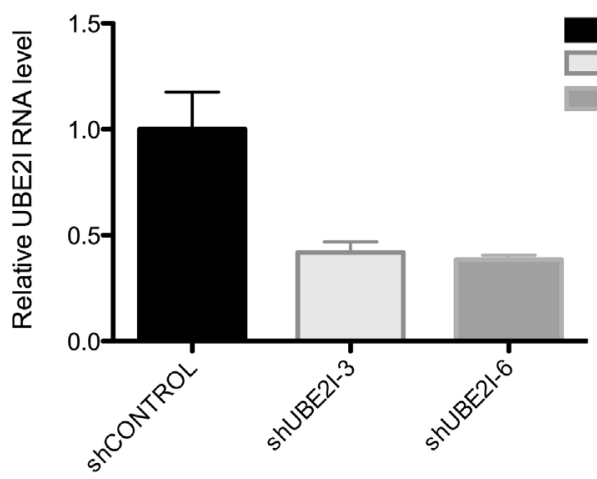

shCONTROL shUBE2I-3 shUBE2I-6

Figure 2: Genome-wide screen for synthetic lethal candidates with MYCER activation. (A) Schematic diagram of screen design. See text for details. (B) Identification of synthetic lethal shRNA with MYCER. Heat map shows the relative enrichment or depletion of each shRNA in all experimental replicates ( 5 for MYC OFF and 5 for MYC ON). The spectrum between red and blue denote the relative representation of each shRNA barcode in the sample compared to the reference (library at $\mathrm{T}=0$ ). (C) Five biological pathways most required for the survival of MCF10A-MYCER. Pathway analysis of the top synthetic lethal candidates (Log2 FC $<-1)$ shows enrichment of genes in five biological pathways. Pathways are listed in order of number of genes appearing from the dataset. (D) UBE2I knockdown is synthetic lethal with MYCER activation. MCF10A-MYCER cells stably expressing two independent shRNA clones targeting UBE2I (shUBE2I-3 and shUBE2I-6) were subjected to competitive survival assays. Fluorescence-based competition assay data are plotted as ratios of \%GFP of MYC ON cells to MYC OFF cells at the given time points for cell lines stably expressing the indicated shRNA. Graph represents the average of three replicates ( $p<0.0001$ between shCONTROL and shUBE2I-3, $p<0.0001$ between shCONTROL and shUBE2I-6). (E) shRNA-mediated stable knockdown of UBE2I. MCF10A-MYCER cells stably expressing shRNA clones targeting UBE2I (UBE2I-3 and UBE2I-6) were subjected to quantitative RT-PCR. Error bars represent the SEM of 3 independent experiments. 
50\% MCF10A-MYCER cells infected with shFBXW7 or shCONTROL were plated in MYC OFF or MYC ON conditions and continuously treated with vehicle or 4OHT at every passage. Cells were harvested at the indicated time points during the competition assay (Figures 3B and $3 \mathrm{C}$ ), and subjected to live cell flow cytometry to measure the percentage of fluorescent surviving cells (Supplementary Figure 3).

Both constitutive and inducible FBXW7 knockdown yielded a significant decrease in viability of cells treated with 4OHT expressing MYCER. Survival of cells infected with control shRNA was not significantly affected by MYCER induction over a period of 23 days, whereas cells with FBXW7 knockdown showed 11\% less GFP signal in the presence of 4 OHT by Day $23(p=0.0006)$ (Figure 3B). When plotted as the MYC ON/MYC OFF ratio of surviving cells, we determined that the constitutive FBXW7 knockdown caused a 21\% decrease in viability ( $\mathrm{p}=0.0003$ ), and the inducible knockdown clones resulted in an average of $53 \%$ decrease in viability compared to control cells $(p<0.0001)$ (Figure $3 \mathrm{C})$. The inducible clones likely yield a more robust reaction due to continuous induction of shRNA by $1 \mu \mathrm{g} / \mathrm{ml}$ doxycycline addition at every passage.
Of note, all the shRNAs used in this secondary screen target different sequences within the FBXW7 mRNA from the shRNAs included the library, confirming that the observed phenotype is due to FBXW7 downregulation. Taken together, these results validate the initial finding from our screen and establish that FBXW7 knockdown is synthetic lethal with MYCER activation.

\section{T47D breast tumor-derived cells are selectively sensitive to FBXW7 knockdown}

Since we confirmed the synthetic lethal effect of FBXW7 knockdown with MYCER activation in MCF10A-MYCER cells, next we elected to examine the correlation between expression of FBXW7 and MYC in various breast tumor subtypes. Analysis of all breast tumors from The Cancer Genome Atlas (TCGA) database did not show any significant correlation between FBXW7 and MYC expression (data not shown). Intriguingly, however, we observed a modest, yet highly significant positive correlation between FBXW7 and MYC expression, exclusively in the Luminal A-subtype of breast cancers ( $\mathrm{rho}=0.28, \mathrm{p}=0.0004)$ (Figure $4 \mathrm{~A})$.
A
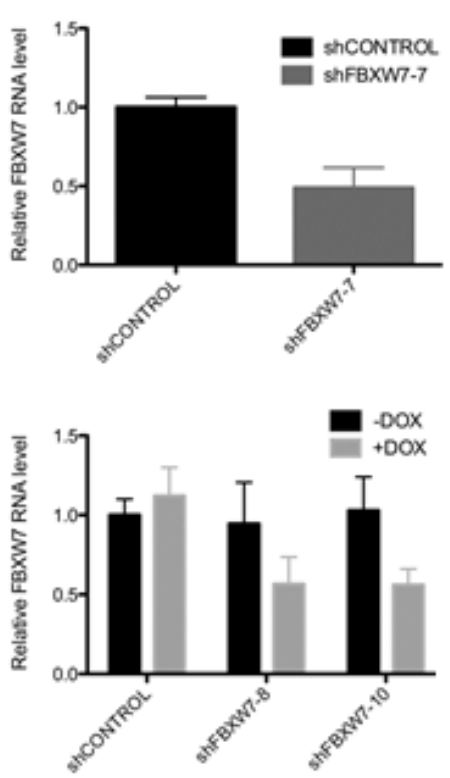

B

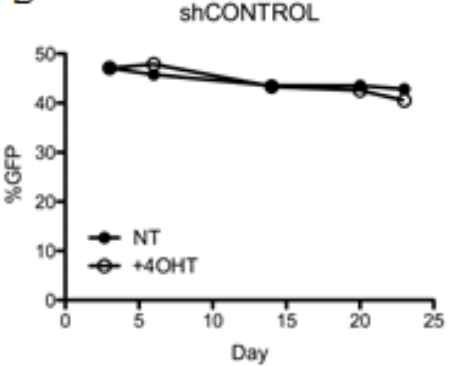

C

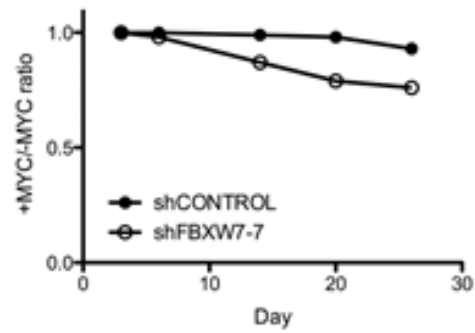

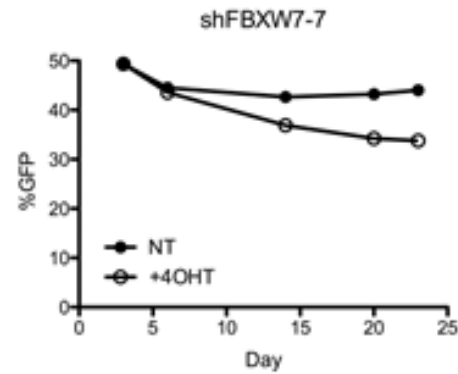

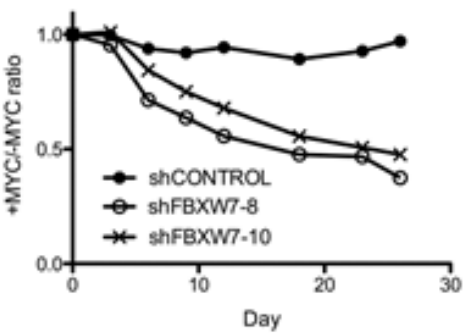

Figure 3: Loss of FBXW7 combined with MYCER activation is lethal. (A) Knockdown of FBXW7 in MCF10A-MYCER cells. FBXW7 expression was inhibited in MCF10A-MYCER cells using lentiviral transduction of shRNA. Constitutive (FBXW7-7) (top panel) and inducible (FBXW7-8 and -10) (bottom panel) knockdown levels were analyzed by quantitative RT-PCR. Error bars represent the SEM of 3 independent experiments. (B) FBXW7 knockdown compromises the viability of MYC ON cells. Fluorescence-based competition assay over 23 days was performed as described in the text. The GFP-expressing population was measured at the indicated time points for untreated (NT) and 4OHT-treated cells. Cells were treated with vehicle or 4OHT every $72 \mathrm{hr}$ for the duration of the experiments. Graphs represent the average of three replicates (NT vs 4OHT not significant for shCONTROL; $p=0.0006$ for shFBXW7-7). (C) Three independent clones of FBXW7 shRNA decrease the viability of 4OHT-induced MCF10A-MYCER cells. Fluorescence-based competition assay data are plotted as ratios of \%GFP of MYC ON to MYC OFF at the given time points. Both constitutive (left panel) and inducible (right panel) FBXW7 knockdown clones show synthetic lethal effect with MYC activation. Graphs represent the average of three replicates ( $\mathrm{p}=0.0003$ between shCONTROL and shFBXW7-7 in left panel; $\mathrm{p}<0.0001$ for both shFBXW7-8 and shFBXW-10 in right panel). 
Luminal A breast cancers are the most prevalent subtype, accounting for approximately $40 \%$ of breast cancer cases [37]. Since this subtype is not normally associated with MYC overexpression, it is possible that Luminal A breast cancers retain sensitivity to MYC protein abundance, unlike MYC-independent breast cancer subtypes.

To expand our observation to another cell type and test if Luminal A-type cells are hypersensitive to FBXW7 knockdown, we achieved stable integration of doxycycline-inducible FBXW7 shRNA in the T47D breast cancer-derived cell line, which harbors a Luminal A-like signature (ER/PR-positive, Her2-negative, overexpresses luminal-specific cytokeratins 8 and 18). Continuous knockdown of FBXW7 over 30 days in T47D cells caused up to $41 \%$ decrease in viability compared to control $(p=0.0076$ and $p=0.01$ for shFBXW7-8 and shFBXW7-10, respectively, compared to shCONTROL) (Figures 4B and 4C), consistent with our results in MCF10A-MYCER cells. We conclude from these observations that our initial findings from the screen using MCF10A-MYCER cells can be extended to the T47D breast cancer cell line in which MYC expression was not experimentally altered and independent of ER activation.

\section{FBXW7 knockdown specifically leads to stabilization of active MYCER}

To explore the mechanism by which FBXW7 down-regulation leads to lethality in MYC expressing cells, we first sought to assess whether down-regulation of FBXW7 resulted in the stabilization of MYCER. To this end, we examined the cellular and chromatin-bound levels of MYCER upon FBXW7 knockdown. Total cellular levels of MYCER were significantly increased upon down-regulation of FBXW7 with either constitutive or inducible FBXW7 shRNAs (3.5 fold and 6.2 fold, respectively, $\mathrm{p}<0.05$ ) (Figure $5 \mathrm{~A}$ ). Moreover, the levels of active, chromatin-bound MYCER detected upon cell fractionation [38] were synergistically increased upon FBXW7 knockdown and MYCER activation (Figure 5B). Chromatin-bound MYCER increased 2-5 fold upon FBXW7 down-regulation and further increased up to 1013.5 fold when MYCER was induced by 4 OHT $(\mathrm{p}<0.1)$ (Figure 5B). To confirm if turnover of MYCER is affected by FBXW7 knockdown, we assessed total MYCER protein levels following cycloheximide treatment to prevent de novo MYCER synthesis in control or FBXW7 knockdown conditions. We observed increased stability of MYCER upon FBXW7 down-regulation, indicative of reduced protein turnover (Figure $5 \mathrm{C}$ and $5 \mathrm{D}$ ). These results suggest that FBXW7 knockdown significantly stabilizes deregulated MYCER, resulting in elevated levels of active chromatin-bound MYCER.

As previously noted, FBXW7 controls the proteasome-dependent degradation of several cellular
A

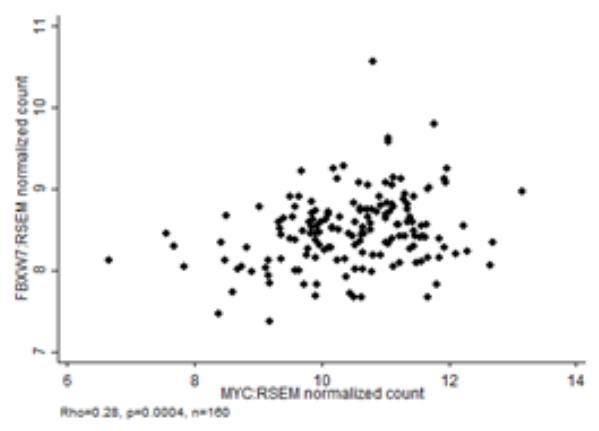

$\mathrm{B}$

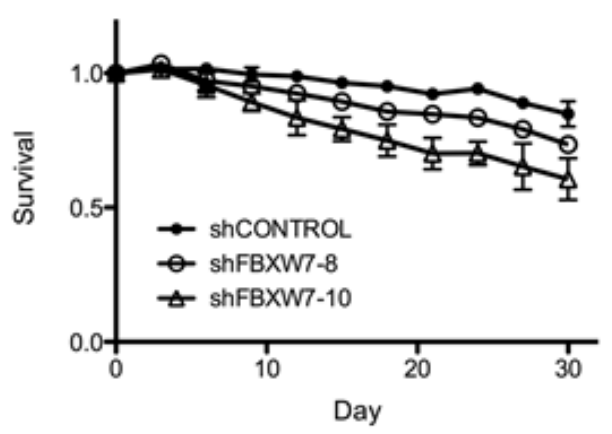

C

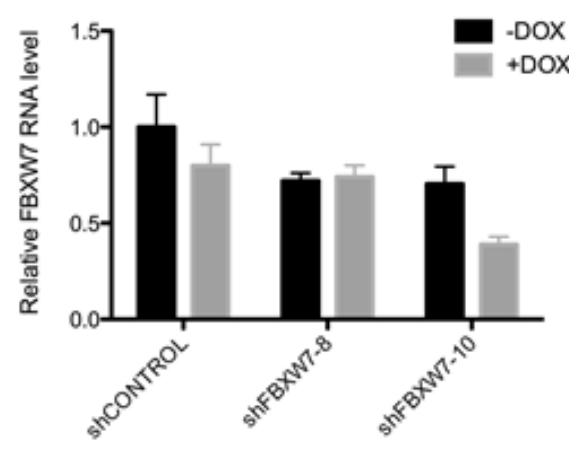

Figure 4: T47D breast cancer-derived cells are selectively sensitive to FBXW7 knockdown. (A) FBXW7 and MYC expression levels positively correlate in Luminal A-type breast cancers. RNAseq (IlluminaHiSeq) data from TCGA breast invasive carcinoma dataset (TCGA_BRCA_exp_ HiSeqV2) were clustered using a "cluster of clusters" approach. Expression of MYC and FBXW7 in LUMINAL A subtypes were estimated in RSEM normalized count and Pearson correlation coefficient (rho) was calculated using STATA. (B) FBXW7 knockdown decreases the viability of T47D cells. Fluorescencebased competition assay data are plotted as ratios of MYC ON to MYC OFF at the given time points. All cells were continuously induced with $1 \mu \mathrm{g} / \mathrm{ml}$ doxycycline at every passage during the assay. Error bars represent the SEM of 3 replicates $(p=0.0076$ between shCONTROL and shFBXW7-8; $\mathrm{p}=0.01$ between shCONTROL and shFBXW7-10). (C) Knockdown of FBXW7 in T47D cells. FBXW7 expression was down-regulated in T47D cells using lentiviral transduction of shRNA. shRNA expression was induced by $1 \mu \mathrm{g} / \mathrm{ml}$ doxycycline and FBXW7 mRNA levels were assessed by RT-PCR. Error bars represent the SEM of 3 replicates. 
A

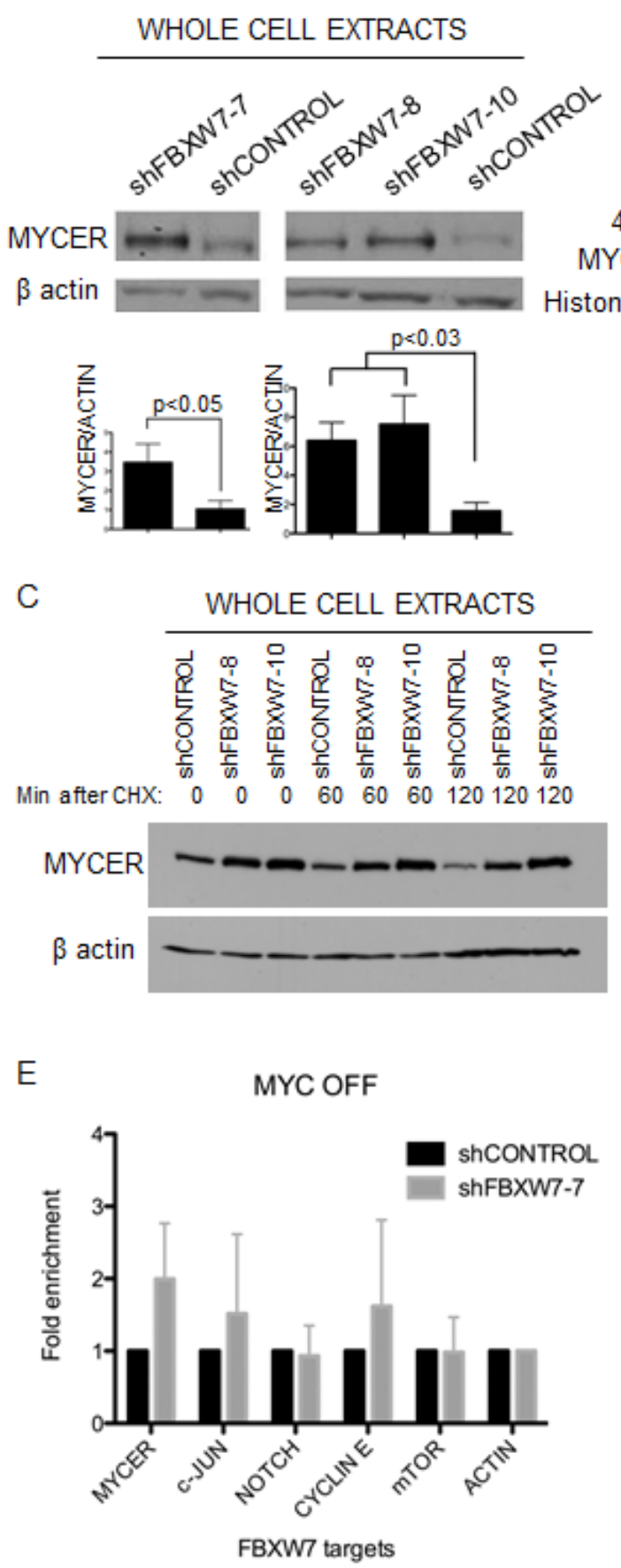

B

\section{CHROMATIN-BOUND FRACTION}
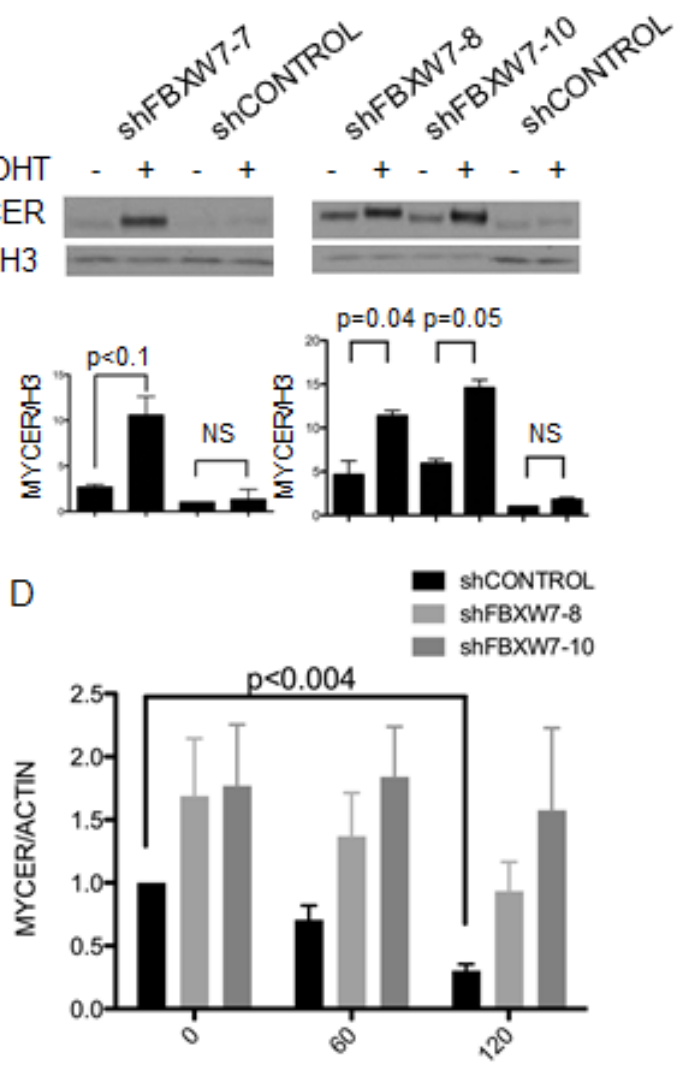

Minutes after $\mathrm{CHX}$

MYC ON

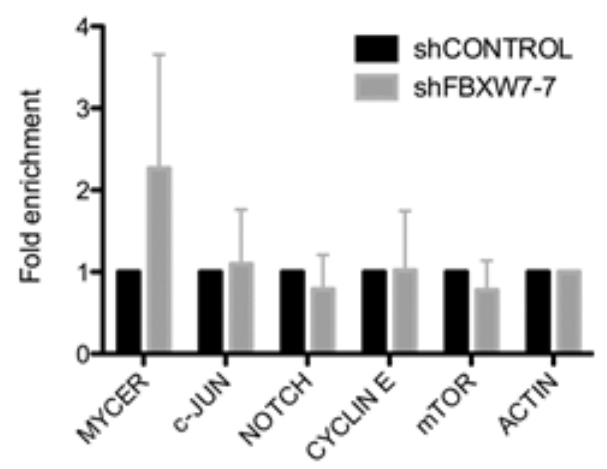

FBXW7 targets

Figure 5: Loss of FBXW7 with MYCER activation results in specific stabilization of active MYCER protein. (A) MYCER protein stability is enhanced in FBXW7 knockdown cells. Whole cell extracts were prepared from MCF10A-MYCER cells with FBXW7 knockdown. Inducible clones were activated with $1 \mu \mathrm{g} / \mathrm{ml}$ doxycycline. Quantified values below each lane are normalized to $\beta$ actin and averaged for 3 experiments. Error bars represent the SEM. (B) Active MYCER is stabilized on chromatin in FBXW7 knockdown cells following 4OHT induction. Cells treated with vehicle or 4OHT were fractionated, and fraction P3 (chromatin-bound) was analyzed on SDS-PAGE. Quantifications are normalized to histone $\mathrm{H} 3$ and values are averages of 3 experiments. Error bars represent the SEM. (C) MYCER protein is stabilized upon FBXW7 knockdown. Indicated cell lines were treated with 200nM 4OHT and $1 \mu \mathrm{g} / \mathrm{ml}$ doxycycline for $24 \mathrm{~h}$, then treated with $50 \mu \mathrm{g} / \mathrm{ml}$ cycloheximide and harvested after 60 and $120 \mathrm{~min}$. Whole cell lysates were run on SDS-PAGE. (D) Western blots from three independent experiments represented in (C) were normalized to $\beta$ actin and quantified. Error bars represent the SEM. (E) FBXW7 knockdown with MYCER activation results in specific stabilization of MYCER. Whole cell extracts were prepared from control or FBXW7 knockdown cells and analyzed on SDS-PAGE followed by Western blot for FBXW7 targets (MYCER, c-Jun, Notch1, Cyclin E, mTOR). Quantifications show the fold enrichment of protein levels in control or FBXW7 knockdown cells normalized to $\beta$ actin. Results are averages of 3 independent experiments and error bars represent the SEM. 
oncogenes which could also be stabilized upon FBXW7 knockdown and account for the observed phenotype [14]. Therefore, we examined the stability of other targets of FBXW7 by Western blot: c-Jun, NOTCH1, CyclinE, and mTOR, upon FBXW7 knockdown (Supplementary Figure 4). We find stabilization of MYCER, c-Jun, and CyclinE upon FBXW7 down-regulation in the absence of MYCER activation (Figure 5E, left). Notably, upon MYCER activation by 4OHT, only MYCER is stabilized when compared to the other FBXW7 targets examined (Figure 5E, right). Similar results were obtained using the inducible FBXW7 knockdown alleles (Supplementary Figure 5). These data suggest that FBXW7 knockdown in the context of MYCER activation leads predominantly to stabilization of MYCER. Our results point to the major role of FBXW7-mediated MYCER degradation for survival of cells with deregulated MYC.

\section{MYCER stabilization results in accumulation of chromatin-bound CDC45 and cells in S/G2 phase}

MYC deregulation triggers DNA damage and genomic instability [6, 39-41]. Therefore, we assessed the consequence of down-regulating FBXW7 together with MYCER activation on DNA damage and apoptosis. We monitored checkpoint activation (phosphorylation of Chk1 by ATR or Chk2 by ATM) and formation of DNA double strand breaks (phosphorylated H2AX), but could not detect a significant synergistic increase in these markers at any timepoint during the four week course of the experiments (Supplementary Figure 6A). Next, we probed for the apoptosis markers cleaved caspase-3, cleaved PARP, and PUMA, but did not detect significant changes by Western blotting (Supplementary Figure 6B). We then examined changes in cell cycle distribution. After four weeks of treatment with 4OHT, we found that FBXW7 knockdown cells in which MYC was deregulated
A

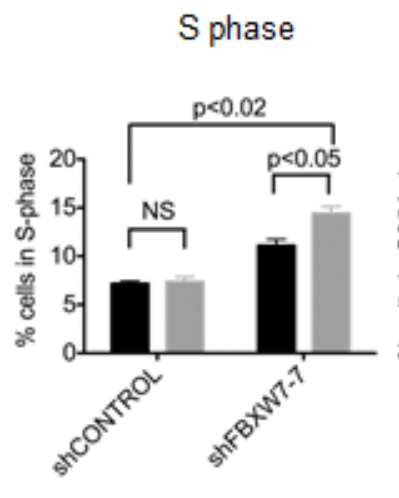

B

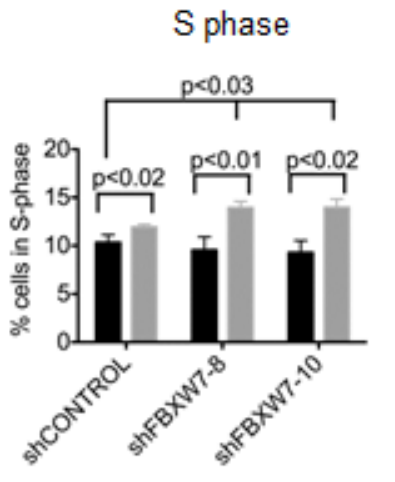

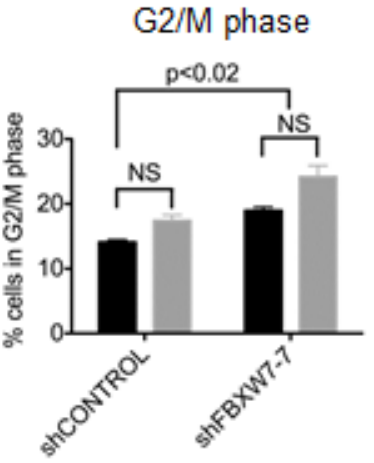

G2/M phase

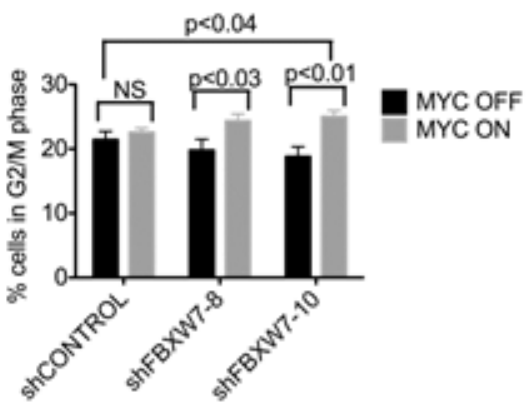

MYC OFF

MYC ON
C

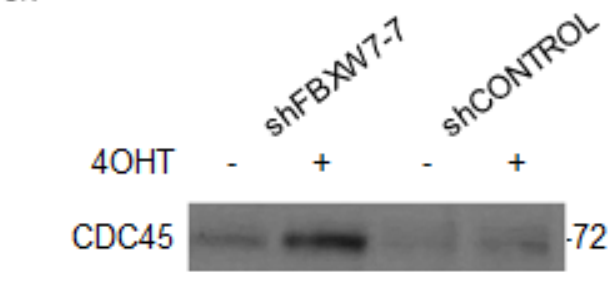

HistoneH3

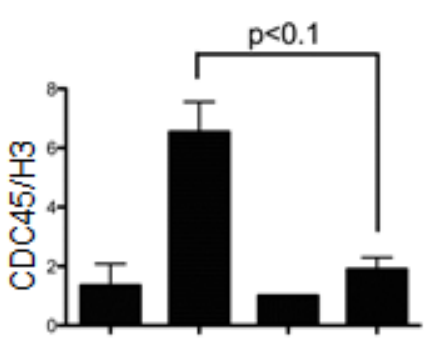

Figure 6: MYCER stabilization results in accumulation of cells in S/G2 phase and chromatin-bound CDC45. (A) Constitutive knockdown of FBXW7 with MYCER activation results in additive accumulation of cells in S and G2/M phase. MCF10AMYCER cells with control or FBXW7 knockdown were cultured for 7 days in the absence or presence of 4OHT (MYC OFF or MYC $\mathrm{ON})$. Cells were fixed and stained with propidium iodide for cell cycle analysis. Results are averages of 3 independent experiments and error bars represent the SEM. (B) Inducible knockdown of FBXW7 with MYCER activation results in accumulation of cells in S and G2/M phase. Control or FBXW7 knockdown cells were cultured for seven days with $1 \mu \mathrm{g} / \mathrm{ml}$ doxycycline and vehicle or $4 \mathrm{OHT}$ every 72 hr. Results are averages of 3 independent experiments and error bars represent the SEM. (C) Loss of FBXW7 with MYCER activation causes accumulation of CDC45 on chromatin. MCF10A-MYCER cells with control or FBXW7 knockdown were cultured for 7 days with or without 4OHT and fractionated. Fraction P3 was analyzed on SDS-PAGE. Shown is a representative image of CDC45 blot, and graph shows the average of 3 independent experiments each normalized to histone H3. Error bars represent the SEM. 
showed synergistic accumulation of cells in $\mathrm{S}$ phase and G2/M phase $(\mathrm{p}<0.05)$ (Figure 6A, 6B, and Supplementary Figure 7). These data suggest that aberrant expression of MYC resulted in slower S-phase progression and/or DNA replication stress, and these phenotypes are exacerbated with FBXW7 knockdown.

We have recently demonstrated that MYCdependent DNA replication stress is directly mediated by CDC45, a component of the replicative DNA helicase that marks active origins of replication. We documented the distribution of chromosomal origins of DNA replication and found that MYC or CDC45 expression both altered their patterns in Xenopus extracts and in B cells [42]. To assess if the cell cycle phenotype we observed could be attributed to aberrant S-phase progression as a result of accumulation of active MYCER on chromatin, we monitored the levels of chromatin-bound CDC45 in FBXW7 knockdown cells. We find that FBXW7 knockdown in the context of MYCER activation by $4 \mathrm{OHT}$ results in a synergistic increase in the levels of chromatinbound CDC45 (6.7 fold increase, $\mathrm{p}<0.1$ ), suggesting increased origin firing in the cells (Figure 6C). Our data suggest that FBXW7 knockdown cells with activated MYCER experience aberrant levels of origin firing during DNA replication, a sign of replication stress, which may contribute to the synthetic lethal phenotype.

\section{DISCUSSION}

Genome-wide screening utilizing RNAi has become a powerful tool to assess genetic interactions in human cells. Three screens specifically designed to identify genes required for cell survival upon MYC deregulation have been previously published [29, 30, 35]. Kessler et al. expressed MYCER in HMEC cells and performed a pooled retroviral shRNA screen [29], Toyoshima et al. used isogenic HFF cells with or without a MYC transgene and performed an siRNA screen [30], and Liu et al. performed a screen using siRNA against the human kinome in U2OS cells [35]. Intriguingly, when we compare the 78 candidates from our screen to these datasets, less than $5 \%$ of genes overlap in pairwise comparisons. Between ours and Kessler's screen, four MYC-SL candidate genes overlap: FBXW7, LAMA2, PRMT8, and ZNF614 [29] (Supplementary Table 1). With Toyoshima's screen [30], we observed one overlap, UBE2I, which we (Figure 2) and Kessler et al. have validated [29, 30] (Figures 2D and $2 \mathrm{E})$. With Liu's screen, we did not observe any specific overlaps [35]. Several reasons may account for these differences. Different studies used normal or cancer cell lines. The mode of MYC deregulation (overexpression vs. inducible) and differences between siRNA and shRNA could also account for some differences. Furthermore, MYC regulates multiple cellular processes and its function as well as the impact of its expression depends heavily on the particular cellular context. Finally, it has been proposed that MYC acts as a general amplifier of activated transcription [43, 44], which could explain in part why MYC may be regulating the expression of different genes in different cell types. Thus, while the differences observed between datasets are puzzling, they demonstrate the importance of studying MYC biology within highly controlled and specific contexts that best mimic physiological systems.

In the present study, we have identified 78 genes which down-regulation is synthetic lethal with MYCER activation in MCF10A-MYCER cells. Though our system utilizes a stably expressed fusion MYCER protein to model MYC deregulation, instead of endogenous MYC, previous studies have established that MYCER does not respond to estrogen and faithfully models MYC deregulation [31]. Nevertheless, we still cannot rule out that some of the MYC-SL candidates we identified may associate with cellular complexes not normally associated with MYC. Nevertheless, MYCER was shown to be a valid model for MYC deregulation in a screen that identified the SUMOylation machinery as a MYC-SL pathway using human mammary epithelial cells [29]. Moreover, we confirmed that T47D cells are hypersensitive to FBXW7 knockdown in the absence of experimental modulation of MYC levels; further supporting the idea that MYCER is a valid model for MYC deregulation.

We have validated FBXW7 as a gene which knockdown causes significantly decreased viability for cells with activated MYCER. Though FBXW7 is known to target several oncogenes for degradation, our findings indicate that knockdown of FBXW7 in the presence of MYCER activation causes preferential stabilization of MYCER. Our data suggest that stabilization of MYCER is critical to cause increased accumulation of FBXW7 knockdown cells in S/G2 phase and loss of viability. Of note, we were not able to detect significant levels of DNA damage or apoptosis markers at any given time throughout the course of the competition assays. This may be attributed to the slow and gradual nature of cell death induction in our experiments, mimicking physiological conditions. We observe, at most, $50 \%$ decrease in viability of FBXW7 knockdown cells compared to control cells over the course of four weeks. We believe that at any given time point, only a small fraction of cells is expressing markers of DNA damage or apoptosis, which is in contrast to what is seen following acute MYC overexpression. Nevertheless, the possibility of senescence or alternative cell death pathway activation cannot be excluded.

FBXW7 is one of only four MYC-SL candidate genes that were identified from both our screen and Kessler's screen, emphasizing its potential significance as a major MYC-SL pathway [29] (Supplementary Table 1). The two other MYC-SL datasets did not include FBXW7, however, the smaller RNAi libraries utilized in these screens may not have included FBXW7 [30, 35]. Notably, Liu's screen that interrogated the human 
kinome identified GSK3- $\beta$, the kinase responsible for a MYC phosphorylation that is required for recognition by FBXW7 [12, 35]. While it has been very challenging to identify common MYC-SL genes and pathways across available datasets[36], these findings suggest that the FBXW7-dependent MYC degradation pathway may be a bona fide MYC-SL pathway shared by multiple cell types.

It is well established that FBXW7 is a crucial component of the SCF-like ubiquitin ligase complex, which targets poly-ubiquitinated proteins for proteasomal degradation. Since many targets of FBXW7 are oncogenes such as MYC, CyclinE, NOTCH1, and c-JUN, FBXW7 is generally considered a tumor suppressor gene. In fact, in human T-cell acute lymphoblastic leukemia (T-ALL), FBXW7 is one of the most frequently mutated genes (approximately $30 \%$ of cases [45]) and mouse models with tissue specific knockout of FBXW7 in various settings develop both hematopoietic and solid tumors [46], corroborating the tumor suppressing functions of FBXW7 in these contexts.

We propose that FBXW7 can also act as a tumor maintenance gene in the context of MYC deregulation. For cells expressing MYC at aberrant levels, the presence of FBXW7 enables their continued proliferation and survival. Consistent with our results, increased accumulation of MYC is responsible for the loss of leukemic stemness in leukemia-initiating cells lacking FBXW7 [47-49]. In a T-ALL mouse model, MYC protein levels in leukemiainitiating cells were found to be heavily dependent on FBXW7 activity, demonstrating that MYC is the major contributor to the FBXW7 phenotype [49]. In agreement, our studies suggest that accumulation of active MYC protein is the major contributor to the synthetic lethal phenotype seen upon FBXW7 knockdown and MYCER activation. Though we have not tested other documented targets of FBXW7 such as SREBP, p100, NRF1, NF1, Mcl-1, KLF5, c-Myb, and Aurora A [46], our results strongly suggest that MYCER is the critical target of FBXW7 contributing to the synthetic lethal phenotype in MYCER activated cells.

While FBXW7 mutations are found in several diverse human cancer types such as T-ALL, cholangiocarcinoma, stomach, colon, pancreas, and endometrium, they are rare in other cancers [50]. In fact, according to Akhoondi et al. [18], FBXW7 mutations appear to be infrequent in breast and ovarian cancers. This could be explained in part by our results suggesting that inactivating mutations of FBXW7 may not be able to coexist with MYC overexpression in the breast context. Interestingly, our analysis suggests that MYC and FBXW7 expression are mildly but significantly positively correlated, specifically in the Luminal A-subtype of breast cancers. Notably, this subtype is typically associated with low to normal MYC expression, suggesting that cells retain physiological regulation of MYC abundance [51]. This is in contrast to cells derived from breast cancer types with MYC overexpression, which can be unresponsive to MYC suppression [52]. Breast cancer cells with low MYC expression, such as Luminal A, may be more sensitive to small fluctuations in MYC protein levels which arise from altered FBXW7 expression.

To gain further insight into the relationship between FBXW7 and MYC in breast, further studies are critical. Nevertheless, our results demonstrating the identification of FBXW7 as a synthetic lethal target in the context of MCF10A-MYCER adds insight to the still enigmatic role of the interaction between FBXW7 and MYC in human cancer initiation, progression, and maintenance.

\section{MATERIALS AND METHODS}

\section{Isolation of MYCER cells}

MYCER was introduced retrovirally using pBabehygro-MYCER into MCF10A cells and transduced clones were selected by the addition of $100 \mu \mathrm{g} / \mathrm{ml}$ Hygromycin B (Roche Holding AG, Basel, Switzerland). Clones were isolated by serial dilution.

\section{Production of lentivirus and shRNA}

Glycerol stocks of lentiviral shRNA constructs (pGIPZ, pTRIPZ) were obtained from Thermo Scientific Open Biosystems (Waltham, Massachusetts, USA) and grown in LB medium with $100 \mathrm{Lg} / \mathrm{ml}$ carbenicillin (Sigma) and $25 \mu \mathrm{g} / \mathrm{ml}$ Zeocin (InvivoGen, San Diego, CA, USA). Clones used were FBXW7-7 (V2LHS_202932), FBXW7-8 (V2THS_89328), FBXW710 (V2THS_203045), UBE2I-3 (V2LHS_171776), and UBE2I-6 (V3LHS_376933). Plasmids were isolated using the E.Z.N.A. Plasmid Miniprep kit (Omega Bio-Tek, Inc., Norcross, GA, USA) and packaged into lentivirus by transfecting (jetPEI by Polyplus-transfection S.A., Illkirch, France) into 293T cells with pMD.G and pCMVR8.91. Viruses were collected in MCF10A media, filtered, and infected into MCF10A in the presence of $8 \mathrm{Lg} / \mathrm{ml}$ polybrene (Sigma) and spin infected for $1 \mathrm{hr}$ at 1000rpm at RT. After $24 \mathrm{hr}$ of incubation, infected cells were selected by the addition of $2 \mu \mathrm{g} / \mathrm{ml}$ puromycin (Sigma).

\section{Cell culture}

MCF10A cells were cultured in DMEM/F12 (Invitrogen, Carlsbad, CA, USA) supplemented with 5\% horse serum (Invitrogen), 20ng/ml EGF (Peprotech, Rocky Hill, NJ, USA), $0.5 \mu \mathrm{g} / \mathrm{ml}$ hydrocortisone (SigmaAldrich Corporation, St. Louis, MO, USA), 100ng/ml cholera toxin (Sigma), 10цg/ml insulin (Sigma), and antibiotics. T47D and 293T cells were cultured in DMEM 
(Invitrogen) supplemented with 10\% FBS (Invitrogen) and antibiotics. All cells were incubated at $37^{\circ} \mathrm{C}$ and $5 \% \mathrm{CO}_{2}$.

\section{Cell lysis and cellular fractionation}

Cells were lysed in RIPA buffer $(150 \mathrm{mM} \mathrm{NaCl}$, $1 \%$ NP40, 0.5\% DOC, $0.1 \%$ SDS, 50mM Tris $\mathrm{pH} 8.0$ ), supplemented with protease and phosphatase inhibitors (Sigma), for $15 \mathrm{~min}$ on ice. Samples were sonicated (2 x $5 \mathrm{~min}$ ) and centrifuged for $10 \mathrm{~min}$ at $4^{\circ} \mathrm{C}$. Cellular fractionation was performed as published by Mendez and Stillman[38].

\section{shRNA screen}

The pooled shRNA screen was carried out using the Thermo Scientific Open Biosystems GIPZ Lentiviral Human shRNA-mir Library as described in RodriguezBarrueco et al [33]. The library was packaged into lentivirus as described above, and MCF10A-MYCER cells were infected at $30 \%$ efficiency. Infected cells were selected with $2 \mu \mathrm{g} / \mathrm{ml}$ puromycin for two passages and divided into 10 independent populations. Five populations were treated with $200 \mathrm{nM} 4 \mathrm{OHT}$ (every $48 \mathrm{hr}$ ) and five were treated with vehicle. After 30 days, genomic DNA of surviving cells was isolated by lysing cells with DNA lysis buffer (1\% SDS, 100mM EDTA pH8.0, 50mM Tris- $\mathrm{HCl} \mathrm{pH} 8,100 \mathrm{nM} \mathrm{NaCl}$ ), treating with RNAse A (Qiagen N.V., Venlo, Netherlands), and purifying DNA with phenol chloroform extraction and isopropanol precipitation. Resulting DNA was subjected to PCR to recover the shRNA and associated barcodes, generating a heterogeneous pooled product of approximately $350 \mathrm{bps}$. The PCR product was gel-extracted and purified, labeled with $\mathrm{Cy} 3$ and $\mathrm{Cy} 5$ (Roche), and hybridized to customized microarrays (Agilent Technologies, Inc., Santa Clara, CA, USA) harboring complementary probes to the shRNA barcodes. Data analysis was then performed as described in $\mathrm{Yu}$ et al [34].

\section{mRNA isolation and RT-PCR}

RNA was isolated using the Nucleospin RNA II kit (Clontech Laboratories, Inc., Mountain View, CA, USA). $1 \mu \mathrm{g}$ of RNA was subjected to reverse transcription using the High Capacity cDNA Reverse Transcription Kit (Applied Biosystems, Life Technologies, Carlsbad, CA, USA). cDNA was used as template for quantitative RTPCR using ABsolute Blue QPCR SYBR Green Low ROX Mix (Thermo Scientific) and Applied Biosystems 7500 Fast (Life Technologies, Carlsbad, CA, USA).

\section{Competition assays}

250000 MCF10A-MYCER cells expressing stably integrated shRNA and 250000 MCF10A-MYCER cells without shRNA were plated together. At the first passage, fluorescent cells were counted by live cell flow cytometry, and replated with either vehicle or 4OHT. At each subsequent passage, remaining percentage of fluorescent cells was analyzed using flow cytometry. All cell sorting was performed with the BD FACSCalibur (BD Biosciences, San Jose, CA, USA).

\section{Luciferase assay}

MCF10A-MYCER cells were plated in 12well plates. After $24 \mathrm{hr}$, at $90 \%$ confluence, they were transfected with MYC reporter and Renilla plasmid and incubated for $48 \mathrm{hr}$ with or without 4OHT. Using the DualLuciferase Reporter Assay System (Promega Corporation, Fitchburg, WI, USA), relative luciferase activity was measured with the GloMax Luminometer (Promega).

\section{Double thymidine block and indirect immunofluorescence}

MCF10A-MYCER cells were plated on sterilized coverslips. After $24 \mathrm{hr}$, cells were incubated in $2.5 \mathrm{mM}$ thymidine for $17 \mathrm{hr}$. After a $7 \mathrm{hr}$ recovery, the second block was administered at $2.5 \mathrm{mM}$ for $14 \mathrm{hr}$. Vehicle or $4 \mathrm{OHT}$ was added $3 \mathrm{hr}$ prior to release. After $1 \mathrm{hr}$ recovery, cells were treated with an $8 \mathrm{~min}$ pulse of $33 ц \mathrm{M}$ BrdU. Immediately, cells were washed and fixed with $4 \%$ paraformaldehyde for 15 min at RT, washed, then permeabilized with $0.2 \%$ Triton- $\mathrm{X}$ in PBS for $5 \mathrm{~min}$ and washed. DNA was denatured in $2 \mathrm{~N} \mathrm{HCl}$ for $20 \mathrm{~min}$ at RT, following neutralization with $0.1 \mathrm{M}$ sodium tetraborate pH8.5. Primary antibody incubation with anti-BrdU (\#555647, BD Pharmingen, San Jose, CA, USA) was performed in PBS- $0.5 \%$ Tween for $30 \mathrm{~min}$ at RT, followed by washing, and secondary antibody incubation with goatanti-mouse-FITC (Jackson ImmunoResearch Laboratories, Inc., West Grove, PA, USA) was performed in PBS$0.5 \%$ Tween for $30 \mathrm{~min}$. Cells were washed and stained for $1 \mathrm{~min}$ with propidium iodide, airdried, and mounted on slides for confocal microscopy. The Zeiss LSM 510 Meta Inverted (Carl Zeiss AG, Oberkochen, Germany) was used for all confocal imaging.

\section{Western blotting and quantification}

Cell lysates were prepared as described, added to 5X Laemmli buffer and heated at $95^{\circ} \mathrm{C}$ for $5 \mathrm{~min}$. Samples were run on Tris-Glycine or NuPAGE Tris-Acetate gels (Invitrogen) and transferred to PVDF membranes at 35V 
for $2 \mathrm{hr}$. Membranes were blocked in PBS-0.5\%Tween$5 \%$ milk for $1 \mathrm{hr}$ and stained with primary antibodies (1:250-1:2000) for $1 \mathrm{hr}$ or overnight, followed by staining with secondary antibodies $(1: 10,000)$ conjugated with HRP (Jackson) for $1 \mathrm{hr}$. After incubation with ECL (Pierce, Thermo Fisher Scientific), blots were exposed to film. ImageQuant 5.2 (Molecular Dynamics) was used for quantification.

\section{mRNA expression analysis}

RNAseq (IlluminaHiSeq) data from TCGA breast invasive carcinoma dataset was downloaded from the cancer browser (TCGA_BRCA_exp_HiSeqV2). Overall, 160 samples with RNAseq data were previously classified as LUMINAL A subtype according to the integrative multiplatform approach described in Nature 2012 (PMID:23000897). Briefly, breast tumors were clustered using a "cluster of clusters" approach based on miRNAs, DNA methylation, copy number, PAM50 mRNA expression, and RPPA expression data. Expression of MYC and FBXW7 in LUMINAL A subtypes were estimated in RSEM normalized count and Pearson correlation coefficient (rho) was calculated using STATA (Stata Statistical Software: Release 12. College Station, TX: StataCorp LP).

\section{Cell cycle analysis}

At the time of harvest, MCF10A-MYCER cells were vortexed in $0.5 \mathrm{ml} \mathrm{PBS}$, and $5 \mathrm{ml}$ of $70 \%$ ethanol was added dropwise for fixing at $-20^{\circ} \mathrm{C}$ overnight. The next day, cells were incubated in $1 \mathrm{ml}$ PBS for $1 \mathrm{hr}$ on ice and centrifuged. To the resulting pellet, RNAse A was added at $1 / 400$, and propidium iodide stock (10mg/ $\mathrm{ml}$, Sigma) was added at 1/1000 for flow cytometry. All analysis was performed with the BD FACSCalibur (BD Biosciences).

\section{Antibodies}

The following antibodies were used for immunostaining: MYC (9E10, Santa Cruz Biotechnology, Inc., Dallas, TX, USA), c-Jun (sc-44, Santa Cruz), cleaved Notch1 (4147, Cell Signaling, ), cyclin E (sc-481, Santa Cruz Biotech), mTOR (2972, Cell Signaling Technology, Inc., Danvers, MA, USA), $\beta$ actin (A2228, Sigma), Histone H3 (9715, Cell Signaling), Cdc45 (EPR5759, Epitomics, Burlingame, CA, USA), Phospho-Chk2 (2661, Cell Signaling), Phospho-H2AX (JBW301, EMD Millipore, Billerica, MA, USA), Cleaved Caspase-3 (9664, Cell Signaling), PARP-1 (sc-8007, Santa Cruz), PUMA (sc28226, Santa Cruz).

\section{Statistics}

All statistical values represented in figures were generated through appropriate t-tests (paired, unpaired, one-sample or two-sample) using Prism 5 (GraphPad Software, La Jolla, CA, USA).

\section{Conflict of interest}

The authors declare no conflict of interest.

\section{ACKNOWLEDGEMENTS}

We thank Dr. David Dominguez-Sola and Dr. Carol Ying for MYC, CyclinE, and $\beta$ actin antibodies, as well as experimental guidance and support. c-Jun antibodies were a gift from Dr. Bin Zheng. Notch1 antibodies were shared by Dr. Adolfo Ferrando's laboratory. mTOR antibody was shared by Dr. Ramon Parsons' laboratory. PARP-1 and PUMA antibodies were shared by Dr. Wei Gu's laboratory. We thank all the mentioned groups for additional assistance and support.

\section{Sources of support}

This work was supported in part by NCI grants CA092245, CA167826 and CA174653.

\section{REFERENCES}

1. Shen $H$ and Laird PW. Interplay between the cancer genome and epigenome. Cell. 2013; 153(1):38-55.

2. Vogelstein B, Papadopoulos N, Velculescu VE, Zhou S, Diaz LA, Jr. and Kinzler KW. Cancer genome landscapes. Science. 2013; 339(6127):1546-1558.

3. Dang CV. MYC on the path to cancer. Cell. 2012; 149(1):22-35.

4. Gabay M, Li Y and Felsher DW. MYC activation is a hallmark of cancer initiation and maintenance. Cold Spring Harb Perspect Med. 2014; 4(6).

5. Meyer N and Penn LZ. Reflecting on 25 years with MYC. Nature reviews Cancer. 2008; 8(12):976-990.

6. Dominguez-Sola D, Ying CY, Grandori C, Ruggiero L, Chen B, Li M, Galloway DA, Gu W, Gautier J and DallaFavera R. Non-transcriptional control of DNA replication by c-Myc. Nature. 2007; 448(7152):445-451.

7. Cowling $\mathrm{VH}$ and Cole MD. The Myc transactivation domain promotes global phosphorylation of the RNA polymerase II carboxy-terminal domain independently of direct DNA binding. Molecular and cellular biology. 2007; 27(6):2059-2073.

8. Liu J and Levens D. Making myc. Current topics in microbiology and immunology. 2006; 302:1-32. 
9. Adhikary S and Eilers M. Transcriptional regulation and transformation by Myc proteins. Nature reviews Molecular cell biology. 2005; 6(8):635-645.

10. Thomas LR and Tansey WP. Proteolytic control of the oncoprotein transcription factor Myc. Advances in cancer research. 2011; 110:77-106.

11. Murphy DJ, Junttila MR, Pouyet L, Karnezis A, Shchors K, Bui DA, Brown-Swigart L, Johnson L and Evan GI. Distinct thresholds govern Myc's biological output in vivo. Cancer cell. 2008; 14(6):447-457.

12. Welcker M, Orian A, Jin J, Grim JE, Harper JW, Eisenman $\mathrm{RN}$ and Clurman BE. The Fbw7 tumor suppressor regulates glycogen synthase kinase 3 phosphorylation-dependent c-Myc protein degradation. Proceedings of the National Academy of Sciences of the United States of America. 2004; 101(24):9085-9090.

13. Yada M, Hatakeyama S, Kamura $T$, Nishiyama $M$, Tsunematsu R, Imaki H, Ishida N, Okumura F, Nakayama $\mathrm{K}$ and Nakayama KI. Phosphorylation-dependent degradation of c-Myc is mediated by the F-box protein Fbw7. The EMBO journal. 2004; 23(10):2116-2125.

14. Welcker M and Clurman BE. FBW7 ubiquitin ligase: a tumour suppressor at the crossroads of cell division, growth and differentiation. Nature reviews Cancer. 2008; 8(2):8393.

15. Thompson BJ, Buonamici S, Sulis ML, Palomero $\mathrm{T}$, Vilimas T, Basso G, Ferrando A and Aifantis I. The SCFFBW7 ubiquitin ligase complex as a tumor suppressor in $\mathrm{T}$ cell leukemia. The Journal of experimental medicine. 2007; 204(8):1825-1835.

16. Sgambato A, Cittadini A, Masciullo V, Di Salvatore M, Graziani C, Rettino A, Valdivieso P, Scambia G, Bianchino G, Zupa A, Improta G and Cifarelli RA. Low frequency of hCDC4 mutations in human primary ovarian cancer. Gynecologic oncology. 2007; 105(2):553-555.

17. Woo Lee J, Hwa Soung Y, Young Kim S, Woo Nam S, Sang Park W, Young Lee J, Jin Yoo N and Hyung Lee S. Somatic mutation of hCDC4 gene is rare in lung adenocarcinomas. Acta oncologica (Stockholm, Sweden). 2006; 45(4):487-488.

18. Akhoondi S, Lindstrom L, Widschwendter M, Corcoran M, Bergh J, Spruck C, Grander D and Sangfelt O. Inactivation of FBXW7/hCDC4-beta expression by promoter hypermethylation is associated with favorable prognosis in primary breast cancer. Breast cancer research : BCR. 2010; 12(6):R105.

19. Kaelin WG, Jr. The concept of synthetic lethality in the context of anticancer therapy. Nature reviews Cancer. 2005; 5(9):689-698.

20. Kaelin WG, Jr. Synthetic lethality: a framework for the development of wiser cancer therapeutics. Genome medicine. 2009; 1(10):99.

21. Wang Y, Engels IH, Knee DA, Nasoff M, Deveraux QL and Quon KC. Synthetic lethal targeting of MYC by activation of the DR5 death receptor pathway. Cancer cell. 2004; 5(5):501-512.

22. Grandori C, Wu KJ, Fernandez P, Ngouenet C, Grim J, Clurman BE, Moser MJ, Oshima J, Russell DW, Swisshelm K, Frank S, Amati B, Dalla-Favera R and Monnat RJ, Jr. Werner syndrome protein limits MYC-induced cellular senescence. Genes \& development. 2003; 17(13):15691574.

23. Moser R, Toyoshima M, Robinson K, Gurley KE, Howie HL, Davison J, Morgan M, Kemp CJ and Grandori C. MYC-driven tumorigenesis is inhibited by WRN syndrome gene deficiency. Molecular cancer research : MCR. 2012; 10(4):535-545.

24. Yang D, Liu H, Goga A, Kim S, Yuneva M and Bishop JM. Therapeutic potential of a synthetic lethal interaction between the MYC proto-oncogene and inhibition of aurora-B kinase. Proceedings of the National Academy of Sciences of the United States of America. 2010; 107(31):13836-13841.

25. Goga A, Yang D, Tward AD, Morgan DO and Bishop JM. Inhibition of CDK1 as a potential therapy for tumors overexpressing MYC. Nature medicine. 2007; 13(7):820-827.

26. Molenaar JJ, Ebus ME, Geerts D, Koster J, Lamers F, Valentijn LJ, Westerhout EM, Versteeg R and Caron HN. Inactivation of CDK2 is synthetically lethal to $\mathrm{MYCN}$ over-expressing cancer cells. Proceedings of the National Academy of Sciences of the United States of America. 2009; 106(31):12968-12973.

27. Hoglund A, Stromvall K, Li Y, Forshell LP and Nilsson JA. Chk2 deficiency in Myc overexpressing lymphoma cells elicits a synergistic lethal response in combination with PARP inhibition. Cell cycle (Georgetown, Tex). 2011; 10(20):3598-3607.

28. Murga M, Campaner S, Lopez-Contreras AJ, Toledo LI, Soria R, Montana MF, D’Artista L, Schleker T, Guerra C, Garcia E, Barbacid M, Hidalgo M, Amati B and FernandezCapetillo O. Exploiting oncogene-induced replicative stress for the selective killing of Myc-driven tumors. Nature structural \& molecular biology. 2011; 18(12):1331-1335.

29. Kessler JD, Kahle KT, Sun T, Meerbrey KL, Schlabach MR, Schmitt EM, Skinner SO, Xu Q, Li MZ, Hartman ZC, Rao M, Yu P, Dominguez-Vidana R, Liang AC, Solimini NL, Bernardi RJ, et al. A SUMOylation-dependent transcriptional subprogram is required for Myc-driven tumorigenesis. Science. 2012; 335(6066):348-353.

30. Toyoshima M, Howie HL, Imakura M, Walsh RM, Annis JE, Chang AN, Frazier J, Chau BN, Loboda A, Linsley PS, Cleary MA, Park JR and Grandori C. Functional genomics identifies therapeutic targets for MYC-driven cancer. Proceedings of the National Academy of Sciences of the United States of America. 2012; 109(24):9545-9550.

31. Littlewood TD, Hancock DC, Danielian PS, Parker MG and Evan GI. A modified oestrogen receptor ligandbinding domain as an improved switch for the regulation of heterologous proteins. Nucleic acids research. 1995; 
23(10):1686-1690.

32. Nesbit CE, Tersak JM and Prochownik EV. MYC oncogenes and human neoplastic disease. Oncogene. 1999; 18(19):3004-3016.

33. Rodriguez-Barrueco R, Marshall N and Silva JM. Pooled shRNA screenings: experimental approach. Methods Mol Biol. 2013; 980:353-370.

34. Yu J, Putcha P, Califano A and Silva JM. Pooled shRNA screenings: computational analysis. Methods Mol Biol. 2013; 980:371-384.

35. Liu L, Ulbrich J, Muller J, Wustefeld T, Aeberhard L, Kress TR, Muthalagu N, Rycak L, Rudalska R, Moll R, Kempa $\mathrm{S}$, Zender L, Eilers M and Murphy DJ. Deregulated MYC expression induces dependence upon AMPK-related kinase 5. Nature. 2012; 483(7391):608-612.

36. Cermelli S, Jang IS, Bernard B and Grandori C. Synthetic Lethal Screens as a Means to Understand and Treat MYCDriven Cancers. Cold Spring Harbor Perspectives in Medicine. 2014; 4(3).

37. Schnitt SJ. Classification and prognosis of invasive breast cancer: from morphology to molecular taxonomy. Modern pathology : an official journal of the United States and Canadian Academy of Pathology, Inc. 2010; 23 Suppl 2:S60-64.

38. Mendez J and Stillman B. Chromatin association of human origin recognition complex, cdc6, and minichromosome maintenance proteins during the cell cycle: assembly of prereplication complexes in late mitosis. Molecular and cellular biology. 2000; 20(22):8602-8612.

39. Felsher DW and Bishop JM. Transient excess of MYC activity can elicit genomic instability and tumorigenesis. Proceedings of the National Academy of Sciences of the United States of America. 1999; 96(7):3940-3944.

40. Vafa O, Wade M, Kern S, Beeche M, Pandita TK, Hampton GM and Wahl GM. c-Myc can induce DNA damage, increase reactive oxygen species, and mitigate $\mathrm{p} 53$ function: a mechanism for oncogene-induced genetic instability. Molecular cell. 2002; 9(5):1031-1044.

41. Karlsson A, Deb-Basu D, Cherry A, Turner S, Ford J and Felsher DW. Defective double-strand DNA break repair and chromosomal translocations by MYC overexpression. Proceedings of the National Academy of Sciences of the United States of America. 2003; 100(17):9974-9979.

42. Srinivasan SV, Dominguez-Sola D, Wang LC, Hyrien O and Gautier J. Cdc45 is a critical effector of myc-dependent DNA replication stress. Cell reports. 2013; 3(5):1629-1639.

43. Lin CY, Loven J, Rahl PB, Paranal RM, Burge CB, Bradner JE, Lee TI and Young RA. Transcriptional amplification in tumor cells with elevated c-Myc. Cell. 2012; 151(1):56-67.

44. Nie Z, Hu G, Wei G, Cui K, Yamane A, Resch W, Wang R, Green DR, Tessarollo L, Casellas R, Zhao K and Levens D. c-Myc is a universal amplifier of expressed genes in lymphocytes and embryonic stem cells. Cell. 2012; 151(1):68-79.
45. Akhoondi S, Sun D, von der Lehr N, Apostolidou S, Klotz K, Maljukova A, Cepeda D, Fiegl H, Dafou D, Marth C, Mueller-Holzner E, Corcoran M, Dagnell M, Nejad SZ, Nayer BN, Zali MR, et al. FBXW7/hCDC4 is a general tumor suppressor in human cancer. Cancer research. 2007; 67(19):9006-9012.

46. Wang Z, Inuzuka H, Zhong J, Wan L, Fukushima H, Sarkar FH and Wei W. Tumor suppressor functions of FBW7 in cancer development and progression. FEBS letters. 2012; 586(10):1409-1418.

47. Takeishi S, Matsumoto A, Onoyama I, Naka K, Hirao A and Nakayama KI. Ablation of Fbxw7 eliminates leukemiainitiating cells by preventing quiescence. Cancer cell. 2013; 23(3):347-361.

48. Reavie L, Buckley SM, Loizou E, Takeishi S, ArandaOrgilles B, Ndiaye-Lobry D, Abdel-Wahab O, Ibrahim S, Nakayama KI and Aifantis I. Regulation of c-Myc ubiquitination controls chronic myelogenous leukemia initiation and progression. Cancer cell. 2013; 23(3):362375.

49. King B, Trimarchi T, Reavie L, Xu L, Mullenders J, Ntziachristos P, Aranda-Orgilles B, Perez-Garcia A, Shi J, Vakoc C, Sandy P, Shen SS, Ferrando A and Aifantis I. The ubiquitin ligase FBXW7 modulates leukemia-initiating cell activity by regulating MYC stability. Cell. 2013; 153(7):1552-1566.

50. Cheng $\mathrm{Y}$ and Li G. Role of the ubiquitin ligase Fbw7 in cancer progression. Cancer metastasis reviews. 2012; 31(12):75-87.

51. Xu J, Chen Y and Olopade OI. MYC and Breast Cancer. Genes \& cancer. 2010; 1(6):629-640.

52. Kang J, Sergio CM, Sutherland RL and Musgrove EA. Targeting cyclin-dependent kinase 1 (CDK1) but not CDK4/6 or CDK2 is selectively lethal to MYC-dependent human breast cancer cells. BMC cancer. 2014; 14:32. 